\title{
O marketing no ciberespaço: a ação de digital influencers no incentivo ao consumo de produtos e serviços por meio do merchandising no Instagram
}

\author{
Afonso Ribas Moreira ${ }^{1}$ \\ Victória Lôbo $o^{2}$ \\ José Luis Caetano da Silva
}

\begin{abstract}
Resumo: Este artigo pretende analisar de que maneira acontece o merchandising nas redes sociais por meio da ação de digital influencers. O objeto de estudo é o Instagram e, principalmente, a sua nova ferramenta: os Insta Stories. Supõe-se que os atores sociais possuem um grande poder de influência e utilizam o aplicativo para publicizar marcas. Para a análise, serviram de exemplos publicações em perfis de artistas com um número expressivo de seguidores. Fez-se uma reflexão sobre ciberespaço e esfera pública, redes sociais e merchandising com o propósito de identificar as estratégias utilizadas pelos influencers em questão para formar opinião sobre determinadas marcas e, sobretudo, incentivar o consumo de produtos. Foi possível perceber que as pessoas famosas, principalmente as do meio artístico, além de praticar a autopromoção, atuam também na condição de digital influencers, promovendo marcas, ora de maneira sutil, ora mais evidente. As estratégias de merchandising baseiam-se na interrelação das ferramentas da rede social e no carisma associado à imagem do influenciador.
\end{abstract}

Palavras-chave: Ciberespaço. Influência digital. Instagram. Merchandising. Redes sociais.

Abstract: This article intends to assay how the merchandising in social networks happens from the action of digital influencers, having as study object the Instagram and, mostly, your new tool: the instastories. It is assumed that such social actors in the network have a considerable influence power on their followers, using the Instagram to publicize brands through practical of merchandising that associate to your private life. To this assay, looked for using as examples publications in profiles of artists with a big number of followers, having as a base a reflection about cyberspace and public sphere, social network and merchandising, in order to identify the strategies used by influencers looked to form opinion about certain brands and products and, especially, to encourage the consumption. It was possible to realize that the famous people besides practicing self-promotion also acting like digital influencers, promoting brands that they use daily both subtly and clarity way. The strategies of merchandising, in this sense, are based in an interrelation between the social network tools and a charismatic association that the public does to the influencer image.

Keywords: Cyberspace. Influencers digital. Instagram. Merchandising. Social Networks.

\section{Introdução}

Desde que surgiu, a internet vem evoluindo e se reinventando de forma quase tão veloz quanto os diversos processos de comunicação do seu âmbito. Essa evolução caracteriza-se, em grande parte,

\footnotetext{
${ }^{1}$ Graduando do curso de Comunicação Social - Jornalismo da Universidade Estadual do Sudoeste da Bahia (UESB). Email: afonsoribass@gmail.com.

${ }^{2}$ Graduanda do curso de Comunicação Social - Jornalismo da Universidade Estadual do Sudoeste da Bahia (UESB). E-mail: vliabff@gmail.com.

${ }_{3}^{3}$ Mestre em Ciências Sociais pela Universidade Federal da Bahia (UFBA) e professor assistente da Universidade Estadual do Sudoeste da Bahia (UESB). E-mail: lucae34@yahoo.com.br.
}

Página 122 Caderno de Ciências Sociais Aplicadas, Vitória da Conquista/BA, vol. 15, n 25, ano 15, p. 122-141, jan/jun 2018. 
pela agregação e produção de um número cada vez maior de ações e atividades humanas, que se transportam dos diversos espaços sociais/públicos tradicionais para a esfera virtual, também conhecida como ciberespaço, o que acontece na medida em que se expandem ou se atualizam as suas incontáveis funções e ferramentas.

Responsável por tais efeitos e mudanças, o ciberespaço trouxe uma nova dinâmica para o estabelecimento e estruturação das relações sociais (agora mediadas pelo meio virtual) e, sobretudo, para a forma como circula a informação, que adquiriu caráter veloz, instantâneo e efêmero. Expandiram-se e ultrapassaram os limites geográficos, desencadeando o que teóricos, tais quais André Lemos e Pierre Levy (2010), denominam “desterritorialização" dos processos de comunicação.

Com isso, a internet se tornou símbolo de um "lugar comum", onde tudo está em contato com tudo, onde todos se encontram e podem interagir. Nela, misturam-se e interligam-se textos, sons, imagens, vídeos e uma diversidade de atuações individuais e coletivas. Assim, ao se aproveitarem das possibilidades e ferramentas da rede, internautas não apenas interagem entre si, mas também trocam conhecimentos, moldam discursos, geram criações coletivas, publicizam produtos, serviços e até identidades.

Hoje, ouve-se dizer que o ciberespaço é o lugar "onde a vida acontece". Nessa nova esfera pública virtual estão atividades que invadiram o âmbito digital e se consolidaram. São exemplos o comércio de bens e serviços, a publicidade, o marketing e a propaganda. Com isso, expandiram-se as possibilidades da lei da oferta e da procura e surgiu uma nova lógica de consumo, baseada muito mais em relações horizontais do que verticais. Ampliaram-se também as estratégias de promoção de produtos, cada vez mais influenciadas pela participação de atores sociais dentro da rede, fortes formadores de opinião e que se sobressaem naquelas que constituem a expressão máxima do ciberespaço: as redes sociais.

A satisfação do consumidor e sua lealdade é uma questão de confiança. Anteriormente, clientes visitavam as lojas para coletar todo tipo de informação que podiam sobre produtos e tomavam suas decisões nessa ida - as lojas físicas eram provavelmente a única fonte de qualquer informação sobre o produto. Hoje em dia, com o aumento do número de fontes de informação, o consumidor digitalmente conectado pode, ativamente, entre suas muitas opções, buscar a melhor informação. Esses consumidores espelham-se em influenciadores através das redes sociais (amigos, família, especialistas ou blogueiros independentes) como fonte de informação segura (DIAS, 2016, p. 9).

Página 123 Caderno de Ciências Sociais Aplicadas, Vitória da Conquista/BA, vol. 15, n² 25, ano 15, p. 122-141, jan/jun 2018. 
Esses atores sociais, denominados digital influencers, são conhecidos pelo número expressivo de seguidores e pela influência que exercem sobre as pessoas. Logo, este artigo pretende analisar de que maneira tais personagens atuam na promoção de produtos e serviços por meio da estratégia de marketing denominada merchandising e, à luz dos pressupostos teóricos de Pierre Levy (1999), Jürgen Habermas (2003), Raquel Recuero (2009) e Dias (2016), entre outros autores, compreender os fatores que determinam esse poder de influência sobre outros usuários. Para tanto, nosso objeto de estudo é o Instagram, ferramenta da rede social conhecida popularmente como "Insta Stories" e utilizada massivamente por digital influencers para realização de merchandising e de propaganda.

\section{Ciberespaço: uma nova dimensão da esfera pública na era do virtual}

O termo "ciberespaço" foi formulado por William Gibson, em 1984, no romance de ficção científica Neuroromancer. Lévy (1999) afirma que, nesse livro, a palavra ciberespaço se refere ao universo das redes digitais, um palco de luta entre as multinacionais, um campo de embates mundiais e uma nova fronteira econômica e cultural.

Geralmente, identifica-se o ciberespaço com a internet e com todo o universo virtual que ela abarca, mas esse novo espaço não se resume àquela ou ao espaço por onde viajam e-mails, mensagens e imagens. Segundo Lévy (1999), o ciberespaço é o novo meio de interação social que surge com base na interconexão mundial de computadores, não se restringindo apenas à infraestrutura material dessa rede, mas abrangendo também o universo de informações que ela abriga e os seres humanos que a alimentam e por ela navegam.

Esse conceito (lugar onde milhões de pessoas percorrem diariamente, criando vínculos, publicizando opiniões, debatendo entre si e produzindo narrativas, etc.) aproxima a noção de ciberespaço da concepção de esfera pública proposta por Jürgen Habermas (2003): um domínio em que pessoas privadas se unem na condição de público. Desse modo, o ciberespaço torna-se uma nova dimensão, porém, diferentemente do contexto concebido por Habermas (2003) - a ascensão dos espaços públicos nos quais os membros da classe burguesa se reuniam para debater assuntos da coletividade. A esfera pública mediada pelo meio virtual é formada por atores sociais ativos, quase integralmente em interação contínua.

Mas essa ainda não é a diferença fundamental entre ambas. O que as difere é o fato de que a esfera pública habermasiana se apresenta tal qual um espaço de interação social dotado de uma

Página 124 Caderno de Ciências Sociais Aplicadas, Vitória da Conquista/BA, vol. 15, n 25, ano 15, p. 122-141, jan/jun 2018. 
dimensão física ou geográfica, enquanto o ciberespaço é um ambiente de comunicação desterritorializado (LEVY; LEMOS, 2010) e que, conforme apontam Isidoro e Silva (2015), propiciam a constituição de relacionamentos além da experiência face a face, não havendo também restrições em relação às trocas comunicativas. Utilizando-se do conceito de esfera pública digital, proposto por Lemos e Levy (2010), os autores ainda afirmam que:

(...) a nova esfera pública não necessita de um espaço físico, pois constitui-se no ciberespaço, no trânsito de dados da internet. Com alcance mundial e sem controle governamental, a esfera pública digital possibilitou uma comunicação de muitos para muitos, num processo interativo no qual todos podem ser emissores e receptores (ISIDORO; SILVA, 2015, p.3).

Aproximar o conceito de esfera pública digital do conceito de esfera pública proposto por Habermas (2003) é perfeitamente possível, tendo em vista a definição do autor "uma rede adequada para a comunicação de conteúdos, tomadas de posição e opiniões” (HABERMAS, 2003, p. 92), ações que estão evidentemente latentes e cada vez mais ativas no ciberespaço.

Moraes (2005 apud BALDANZA; ABREU, 2006) afirma que o ciberespaço se configura tal qual um conjunto vivo de significações, em que tudo está em contato com tudo: os hiperdocumentos entre si, as pessoas entre si e os hiperdocumentos com as pessoas. A hipertextualidade, fundamento essencial do ciberespaço, aloca um número incontável de informações, conhecimentos e mensagens para a grande rede e torna possível a interconexão entre elas. $O$ indivíduo tem à sua disposição uma verdadeira memória eletrônica, que parece não se acabar. Há sempre algo mais para procurar ou para ver.

Ao mergulhar no ambiente do ciberespaço, o usuário experimenta uma sensação de "abolição do espaço" e circula em um território transnacional, desterritorializado, no qual as referências de lugar e caminhos que ele percorre para se deslocar de qualquer ponto a outro modificam-se substancialmente (SILVA; TANCMAN, 1999, p. 58-59).

São essas características apontadas por Silva e Tancman (1999) que definem o ciberespaço como um lugar abstrato e semiótico. Dessa forma, a presença de aspectos comuns da vida social nesse espaço é bastante forte, pois os indivíduos usam das facilidades e funções da internet para romper com as fronteiras físico-espaciais, o que antes já acontecia com a televisão e o rádio, mas que agora se intensifica em um ambiente onde se convergem diferentes tipos e formatos de mídia.

Página 125 Caderno de Ciências Sociais Aplicadas, Vitória da Conquista/BA, vol. 15, n 25, ano 15, p. 122-141, jan/jun 2018. 
Soares (2014) ressalta que a convergência digital não representou apenas a circulação de um grande fluxo de informações em múltiplas mídias, mas uma mudança cultural, em que os usuários foram estimulados não apenas a usufruir do acesso a um maior número de informações, mas também a trocar ideias, se relacionar, interagir e, consequentemente, produzir e disponibilizar seus próprios conteúdos no ciberespaço. Passaram ainda a contribuir para formar opiniões acerca de diversos assuntos, bens, serviços e produtos, na condição de mediadores de estratégias de marketing. Isso acontece principalmente quando esses usuários se inserem na dinâmica das redes sociais. Com a emergência do ciberespaço, elas se consolidaram a expressão máxima de interação social na rede e, recentemente, ampliaram suas funções, atuando também na condição de espaços de mediação de capitais e bens simbólicos.

\section{A dinâmica das redes sociais enquanto espaços de interações mediadas}

O número de redes sociais aumentou expressivamente desde o seu surgimento. Igualmente, a quantidade de pessoas que passaram a utilizá-las também cresceu de forma massiva e veloz. Além disso, ampliaram-se as suas ferramentas, o que permitiu a execução de mais funções do que a simples comunicação entre os usuários.

A perspectiva geral é que as redes sociais são espaços de interação. Recuero (2009) explica que uma rede é uma metáfora para observar os padrões de conexão de um grupo social, com base nas conexões estabelecidas entre os diversos atores presentes em seu âmbito. Segundo a autora, não é possível isolar os atores sociais nem as suas conexões. Os primeiros atuam de forma a moldar as estruturas sociais, mediante a interação e a constituição de laços sociais. Porém, ela ressalta que:

(...) devido ao distanciamento entre os envolvidos na interação social, principal característica da comunicação mediada por computador, os atores não são imediatamente discerníveis e por isso o tratamento dos mesmos deve ser repensado para que se trabalhe com representações dos atores sociais, ou com construções identitárias do ciberespaço (RECUERO, 2009, p. 25).

Quando se pensa em rede social, a atuação na internet assume a forma que o usuário pretende. Ele constrói um perfil de si mesmo, não necessariamente a representação de sua real identidade. Ou seja, na condição de espaço construído pelo ator social, no qual ele pode (ou não) expressar 
características que representem sua real personalidade, a rede torna-se um fator constituinte de representações imbricadas por meio da interação.

(...) a interação, como tipo ideal, implicaria sempre uma reciprocidade de satisfação entre os envolvidos e compreende também as intenções e atuações de cada um. Interações não são, portanto, descontadas dos atores sociais. São parte de suas percepções do universo que os rodeia, influenciadas por elas e pelas motivações particulares desses atores (RECUERO, 2009, p. 31).

O foco do estudo das redes sociais são as conexões, uma vez que é a variação destas que altera a estrutura dos grupos e gera as diversas formas de sociabilidade e eventos do ciberespaço, incluindo o fluxo de informações que determinam estratégias de merchandising no seu âmbito. Recuero (2009) destaca que há particularidades inerentes ao ciberespaço e às suas ferramentas de comunicação. Dessa forma, existem fatores que os diferenciam das interações estabelecidas no espaço físico simbólico.

O primeiro deles é que os atores não se dão imediatamente a conhecer. Não há pistas da linguagem não verbal e da interpretação do contexto da interação. É tudo construído pela mediação do computador. O segundo fator relevante é a influência das possibilidades de comunicação das ferramentas utilizadas pelos atores. Há multiplicidade de ferramentas que suportam essa interação e o fato de permitirem que a interação permaneça mesmo depois do ator estar desconectado do ciberespaço. Esse fato permite, por exemplo, o aparecimento de interações assíncronas (RECUERO, 2009, p. 32).

Tanto as comunicações síncronas quanto as assíncronas estão presentes no âmbito virtual. A primeira é aquela que simula uma interação em tempo real, os chats no Facebook, por exemplo. "Deste modo, os agentes envolvidos têm uma expectativa de resposta imediata ou quase imediata, estão ambos presentes no mesmo momento temporal" (RECUERO, 2009, p. 32). A comunicação assíncrona é aquela em que a expectativa de resposta não é imediata. Segundo Recuero (2009), por não estar presente no momento temporal da interação, o ator pode respondê-la posteriormente, o que pode ser exemplificado pelo Insta Stories do Instagram.

Recuero (2009) lembra outra característica das interações mediadas por computador: a capacidade de migração. De acordo com a pesquisadora, a interação dos atores sociais pode ocorrer em diversas plataformas de comunicação, como em uma rede de blogs ou por meio do Twitter, por exemplo. Tal migração pode também auxiliar na percepção da multiplicidade das relações, um

Página 127 Caderno de Ciências Sociais Aplicadas, Vitória da Conquista/BA, vol. 15, n² 25, ano 15, p. 122-141, jan/jun 2018. 
indicativo da presença de laços fortes na rede, os quais influenciam diretamente o poder de influência de determinados atores sociais.

Freitas e Maia (2014) complementa esse pensamento ao afirmar que, na atualidade, a tecnologia de rede nos permite participar de forma efetiva, imediata e inovadora dos conteúdos emitidos pela grande mídia. Dessa forma, os indivíduos tornam-se, ao mesmo tempo, receptores e emissores, produtores e consumidores de mensagens, fazendo com que a comunicação deixe, definitivamente, de ser linear. Segundo as autoras, nesse aspecto, as redes sociais possuem uma função importante, pois estão intimamente ligadas ao compartilhamento de informações, conhecimentos, interesses e esforços em busca de objetivos comuns, principalmente quando tais objetivos tratam da promoção de serviços e produtos. Tais fatores são determinantes para a elaboração, por exemplo, das estratégias de merchandising e de propaganda no ciberespaço e, de modo ainda mais latente, nas redes sociais.

\section{O merchandising no contexto virtual: expressões e características}

O merchandising é uma prática que migrou dos meios de comunicação tradicionais (televisão e rádio) para a internet. Comum nas redes sociais, ele aparece por meio de vídeos, de publieditoriais, etc., maneiras mais efetivas, mas também mais claras de marketing.

Merchandising é qualquer técnica, ação ou material promocional usado no ponto de venda que proporcione informação e melhor visibilidade a produtos, marcas ou serviços, com o propósito de motivar e influenciar as decisões de compra dos consumidores (SAMPAIO; BARUQUE-RAMOS, 2014, p. 6).

Como meio de compra e venda, a internet gera, cada vez mais, investimentos em marketing. À medida que as pessoas passam a confiar no comércio eletrônico e acessam os variados sites, estes vão adquirindo credibilidade e surge a possibilidade de patrocínio. Na opinião de Toledo, Nakagwa e Yamashita (2002), devido a esse dinamismo, os patrocinadores podem manter a informação atualizada de maneira ágil.

Com o avanço tecnológico, o surgimento de lojas virtuais e o advento das redes sociais, o merchandising foi-se tornando, cada vez mais, uma estratégia utilizada no ciberespaço para atrair consumidores para determinadas marcas. Nele, as empresas viram a possibilidade de adquirir consumidores, considerando a quantidade de acessos de determinados sites ou blogs.

Além do empresarial, as redes sociais são também palco do marketing pessoal. Pessoas comuns e,

Página 128 Caderno de Ciências Sociais Aplicadas, Vitória da Conquista/BA, vol. 15, n 25, ano 15, p. 122-141, jan/jun 2018. 
principalmente, famosas utilizam-se da imagem e da trajetória para chegar até outras sem causar estranhamento, pois, dessa forma, o público se sente mais próximo. Nesse novo contexto, as relações pessoais e de consumo se modificam:

É a sociedade do espetáculo e das imagens, que mistura realidade ao entretenimento e que, de uma forma ou de outra, cria uma narcose dos sentidos. Mesmo nos informando mais sobre o mundo, a sociedade midiática massiva e do espetáculo nos deixa sem ação, ou melhor, só nos oferece uma ação: consumir e constatar, a depender do ponto de vista, as delícias ou mazelas do mundo (LEMOS, 2009, p. 2).

A esfera pública volta-se, portanto, para o capital, conforme ressalta Habermas (2003). Igualmente, a opinião pública depende da sociedade do espetáculo e de quanto esse espetáculo agrada os prováveis consumidores.

Ao perceber isso, algumas empresas começaram a direcionar a ação de indivíduos intitulados "influenciadores digitais" para se promover. O influenciador recebe determinado produto e o mostra a seu público, que, consequentemente, será estimulado a consumi-lo. Quanto mais favorável a concepção dos influenciados em relação ao influenciador, mais investimento empresarial. A imagem, assim, se tornou um negócio.

\section{A ação dos digital influencers}

A forma com que um indivíduo consome determinada marca, bem ou serviço, ou toma para si a ideia ou o comportamento de uma pessoa pública, varia de pessoa para pessoa e depende do produto, da importância e do discurso do influenciador.

Primeiro o influenciador promove a sua própria imagem, em seguida, o produto ou serviço de determinada marca. Conforme explicou Dias (2016), digital influencers são fomentadores do consumo em suas mais diferentes formas: espaço, roupas, alimentos, modo de vida etc.

Um digital influencer pode ser um blogueiro que escreve sobre vida saudável e que, além de vender seu modo de vida, adota estratégias de marketing para empresas de diferentes ramos: lojas de alimentos saudáveis, academias, marcas de roupas para a prática de exercícios, entre outros. Pode também ser uma pessoa com uma longa carreira artística, público cativo e um grande número de seguidores nas redes sociais. Ao mostrar seu dia a dia em fotos ou vídeos, surge, ainda que de forma mais sutil, a chance de um merchandising.

Página 129 Caderno de Ciências Sociais Aplicadas, Vitória da Conquista/BA, vol. 15, n 25, ano 15, p. 122-141, jan/jun 2018. 
A capacidade de conjugar de modo efetivo o fascínio do mundo dos espetáculos e a interatividade das redes de comunicação instantânea e ubíqua está na base de estratégias como o bu₹z e o viral, pedras de toque da estreita imbricação que se configura nas redes sociais digitais entre negócios, comunicação e sociabilidade (CASTRO, 2012, p.136).

Dessa forma, conforme Guedes (2010), o espaço público é um local de interação e de exercício dos direitos civis. Nele, configura-se uma nova forma de poder que "se relaciona com os recursos técnicos, o conhecimento e o prestígio empregados na relação com o outro, para influenciar pessoas e grupos” (GUEDES, 2010, p. 10).

A presença da esfera pública no campo virtual é muito importante para a opinião pública, por ser esse um espaço de discussão sobre a sociedade. Porém, pelo viés capitalista e comercial, o poder, que, nessa circunstância, não significa capital monetário e sim discursivo, é uma questão a ser repensada.

O ator "mercado", no processo de interação com outras formas de poder no espaço público, interfere no processo comunicacional e, por conseguinte, na organização e articulação da sociedade. Apesar de não ser apenas mais uma mídia, a internet abriga mídias e é um grande mercado aberto, propício à mercantilização de qualquer coisa, inclusive do que nunca antes havia sido mercantilizado (GUEDES, 2010, p. 13).

Ser digital influencer, em determinado momento, tornou-se um nicho específico de atuação. Cada vez mais, pessoas e marcas utilizam o potencial desse espaço para promover bens e serviços e se autopromover. A estratégia de marketing é investir naquele indivíduo que atinge o maior número de seguidores. Quanto mais seguidores, mais consumidores para os produtos anunciados. Entre as redes sociais mais utilizadas para esse fim está o Instagram, uma importante ferramenta de comunicação de empresas nos últimos anos, visto que serve de estímulo para o consumo de produtos e serviços. Muitas vezes, os digital influencers são os responsáveis por fazer a ponte entre empresa e consumidor.

\section{Práticas de merchandising no Instagram}

O elemento que mais atrai a atenção do consumidor na rede é a imagem. Dessa forma, o Instagram não só é a mídia mais utilizada para promover marcas e produtos, mas também a que mais se adéqua ao objetivo das estratégias de marketing e merchandising na esfera pública digital. $\mathrm{Na}$ ação de determinado influenciador digital, funciona tal qual uma máquina de visibilidade, em que texto e som

Página 130 Caderno de Ciências Sociais Aplicadas, Vitória da Conquista/BA, vol. 15, n 25, ano 15, p. 122-141, jan/jun 2018. 
também a constituem, mas na condição de elementos complementares, apenas reforçando o poder da imagem.

Dias (2016, p. 9-10) observa que, no Instagram, os digital influencers podem advogar a favor de uma marca de três maneiras:

1. Direta e propositalmente (com remuneração): essas situações ocorrem quando postagens são feitas mencionando diretamente as marcas [...]. 2. Indireta e propositalmente (com remuneração): nesse contexto, não se utiliza tags, hashtags e nem textos enaltecendo os benefícios de determinada marca ou empresa. Quando se trata de estabelecimentos comerciais, usualmente adiciona-se sua localização e o influenciador simplesmente usufrui do serviço ou marca [...]. 3. Indiretamente (sem remuneração): pode ser observado com certa frequência em perfis de pessoas muito seguidas e autoridades em determinado assunto. Tais pessoas, a pedido de seus seguidores, podem vir a adicionar tags ou mesmo descrever o que usam quando solicitados para saciar a curiosidade de sua fanbase, mesmo que tenham usufruído da marca com seu próprio dinheiro [...].

Entre as redes sociais, o Instagram é a que mais gera respostas imediatas a determinado estímulo, como a publicação de uma foto ou a ação de seguir um perfil com a intenção de gerar uma atitude recíproca, por exemplo. O aplicativo foi desenvolvido em 2010 por engenheiros de programação, o norte-americano Kevin Systrom e o brasileiro Mike Kriege, com o objetivo de ser utilizado em smartphones, basicamente em duas das plataformas mais usadas atualmente: sistemas móveis IOS e Android. A intenção dos criadores "era resgatar a nostalgia do instantâneo cunhada ao longo de vários anos pelas clássicas polaroids, câmeras fotográficas de filme, cujas fotos revelavam-se no ato do disparo" (PIZA, 2012, p. 7).

Com o tempo e o surgimento de outras ferramentas integradas às redes sociais, o Instagram, que até então consistia basicamente no compartilhamento de fotos e na interação privada por meio do chamado "Direct", atualizou-se e passou a oferecer aos usuários novas formas de interação e publicização. Entre elas, destaca-se o Insta Stories, com uma função bastante semelhante à de outro aplicativo: o Snapchat.

O Insta Stories permite aos usuários do Instagram publicar fotos e vídeos mais relacionados ao cotidiano e que não são submetidos a tratamento estético prévio. Porém, essas postagens se autodestroem vinte e quatro horas após a publicação, aspecto que as difere das postagens do Feed, a zona principal do aplicativo. 
O Insta Stories fortaleceu o Instagram e passou a ser amplamente utilizados pelos usuários, sobretudo pelos digital influencers, que viram nesse mecanismo uma forma de promover marcas e produtos e estimular o consumo entre seus seguidores. Pelo fato de evidenciarem a vida privada de influenciadores digitais, revelando o cotidiano, a intimidade e a rotina de celebridades, por exemplo, o Insta Stories tem o poder de persuadir de maneira mais efetiva quando utilizado para merchandising.

Muitos influenciadores digitais, principalmente celebridades, vêm utilizando o Insta Stories para essa prática. "Celebridades sempre foram exploradas pela mídia para alcançarem as pessoas, trazerem popularidade e ampliarem as vendas/notoriedade de designados serviços, estabelecimentos ou produtos" (DIAS, 2016, p. 9). Com base nesse pressuposto, nosso objetivo é identificar a presença de merchandising no Insta Stories de quatro celebridades, tendo em vista o poder de influência dessas pessoas sobre os usuários, potenciais consumidores. Serviram de fonte os Insta Stories das cantoras Ivete Sangalo e Solange Almeida e os das atrizes Bruna Marquezine e Fernanda Souza, todos publicados nos dias 03 e 04 de junho de 2017.

\section{Procedimentos metodológicos}

Levando em conta o seu objetivo, este estudo tem natureza teórico-empírica, com abordagem qualitativa e caráter exploratório. De acordo com Gil (2008), utiliza-se a pesquisa exploratória geralmente quando a temática é pouco explorada, quando se trata de um objeto pouco investigado no campo científico, o que torna difícil a formulação de hipóteses precisas e operacionalizáveis. "Pesquisas exploratórias são desenvolvidas com o objetivo de proporcionar visão geral, de tipo aproximativo, acerca de determinado fato" (GIL, 2008, p. 27).

O ponto de partida foi identificar práticas de merchandising em perfis de famosos (artistas, músicos, atores etc.) no Instagram por meio da ferramenta denominada Insta Stories. Após definição do tema do artigo, fez-se um levantamento bibliográfico dos principais conceitos a serem abordados: ciberespaço, esfera pública, redes sociais, merchandising, digital influencers etc. Para tanto, serviram de fonte livros, artigos publicados em periódicos, em anais de congressos etc.

O método observacional (GIL, 2008) norteou o estudo empírico dos perfis em questão e a observação simples foi o instrumento para a coleta de dados:

Página 132 Caderno de Ciências Sociais Aplicadas, Vitória da Conquista/BA, vol. 15, n 25, ano 15, p. 122-141, jan/jun 2018. 
Embora a observação simples possa ser caracterizada como espontânea, informal, não planificada, coloca-se num plano científico, pois vai além da simples constatação dos fatos. Em qualquer circunstância, exige um mínimo de controle na obtenção dos dados. Além disso, a coleta de dados por observação é seguida de um processo de análise e interpretação, o que lhe confere a sistematização e o controle requeridos dos procedimentos científicos (GIL, 2008, p. 101).

Foram analisadas publicações de quatro artistas conhecidas nacionalmente, com uma quantidade elevada de seguidores, fator determinante para considerá-las digital influencers. Uma vez que as stories publicadas no Instagram se autodestroem após vinte e quatro horas, os perfis em questão foram analisados entre os dias 27 de maio e 4 de junho de 2017. O intuito foi verificar a presença e as características do merchandising na rede social. As amostras constituem publicações de cada perfil no dia quatro de junho, uma delas havia sido postada no dia anterior.

Considerando a imprevisibilidade de postagens com práticas de merchandising, a observação simples assumiu caráter assistemático, ou seja, "aquela que se realiza sem planejamento e sem controle anteriormente elaborados, como decorrência de fenômenos que surgem de imprevisto" (RAMPAZZO, 2005, p. 106). A análise e a interpretação dos dados seguiram a abordagem qualitativa, segundo a qual, o interesse dos pesquisadores ao verificar um determinado objeto de estudo está em "verificar como ele se manifesta nas atividades, nos procedimentos e nas interações cotidianas” (OLIVEIRA, 2011, p. 25).

\section{Uma análise dos Insta Stories de digital influencers}

Em 2016, uma pesquisa da revista "Seleções", em parceria com a Datafolha, colocou Ivete Sangalo entre as cantoras mais confiáveis do país. Segundo Bourdieu (2003), a pesquisa de opinião é um instrumento de ação política. Dessa forma, quando se julga um artista dessa maneira, mesmo que a pesquisa não os represente de início, a percepção das pessoas sobre ele pode mudar.

A pessoa pública é uma organização e, se a confiança depositada nela atinge um grau alto e estável, a possibilidade de conseguir mais investimento (tanto cultural quanto capital) é maior. Ivete Sangalo soma mais de quarenta e um milhões de seguidores em suas redes sociais. Desses, 16,2 milhões são do Instagram. "Como a audiência é mais facilmente medida na rede, é possível visualizar as conexões e as referências a um indivíduo, a popularidade é mais facilmente percebida" (RECUERO, 2009, p. 111).

Página 133 Caderno de Ciências Sociais Aplicadas, Vitória da Conquista/BA, vol. 15, n 25, ano 15, p. 122-141, jan/jun 2018. 


\section{- Cadernos de Ciénclas SOCIAIS APLICADAS}

Ao consideramos os preceitos de Recuero (2009), percebemos que tal popularidade revela a presença de uma espécie de capital social no ciberespaço. Essa soma é visível na capacidade da cantora, e de outros famosos, de causar impressão e formar opinião sobre marcas e serviços. Com base nisso, podemos classificar o perfil de Ivete Sangalo no Instagram um nó centralizado na rede, definido justamente em função da sua popularidade. Essa centralidade, no caso, ocorre "porque há mais pessoas conectadas a ele e, por conseguinte, esse nó poderá ter uma capacidade de influência mais forte que outros nós na mesma rede" (RECUERO, 2009, p. 113).

Na condição de digital influencer, "Veveta" (@ivetesangalo), conforme consta no Instagram, utiliza tanto as publicações em seu Feed quanto os vídeos rápidos e as fotos postadas em seu Insta Stories. O conteúdo normalmente relaciona-se ao seu modo de vida de maneira geral, alimentação, realização de shows etc. No tocante à rotina, destacam-se os produtos que a artista recebe das marcas e os lugares que ela frequenta.

Figura 1: Merchandising no Insta Stories de Ivete Sangalo

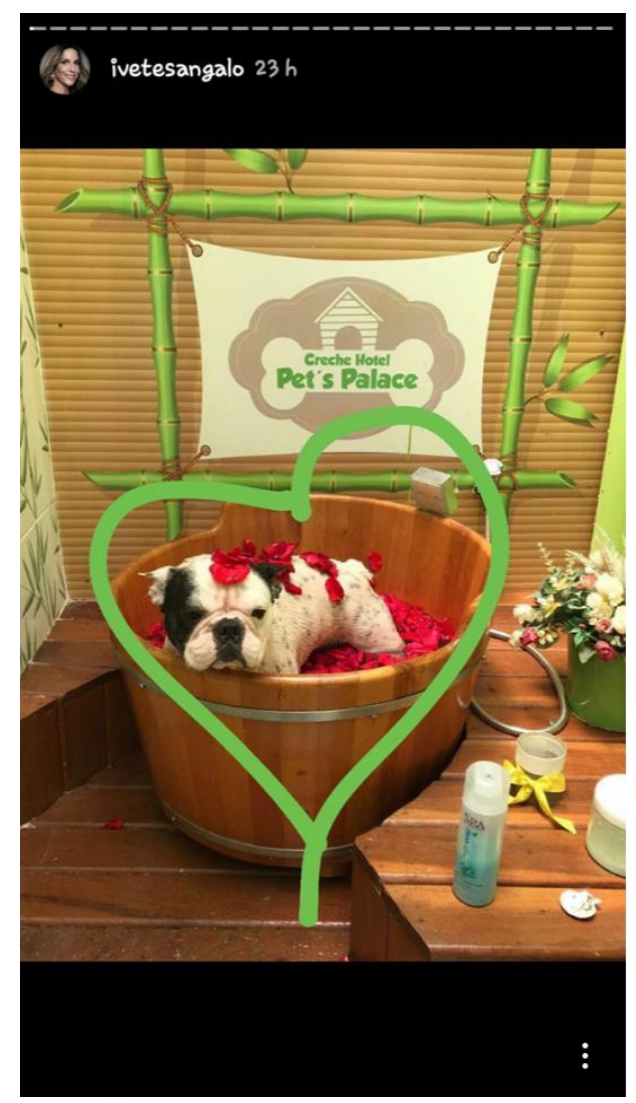

Fonte: Instagram

Página 134 Caderno de Ciências Sociais Aplicadas, Vitória da Conquista/BA, vol. 15, n 25, ano 15, p. 122-141, jan/jun 2018. 


\section{- Cadernos de Ciências SOCIAIS APLICADAS}

Nessa foto, a cantora mostra a sua cachorra em uma pet shop, cuja logomarca e nome estão visíveis. Trata-se de uma forma sutil de merchandising, classificado, com base na categorização de Dias (2016), de indireto e proposital. Uma vez que Ivete possui credibilidade e um grande número de seguidores, as empresas aproveitam da sua capacidade de angariar pessoas para promover suas marcas. Esse tipo de marketing produz o mesmo efeito que as propagandas com pessoas públicas, mas é ainda mais eficiente, pois a proximidade estabelecida pelas redes sociais faz com que os seguidores acreditem que ela realmente usa a marca.

Outro exemplo de merchandising via Stories do Instagram aparece no perfil da atriz e apresentadora Fernanda Souza (@fernandasouzaoficial).Carismática, ela possui onze milhões de seguidores na rede e utiliza o Insta Stories com frequência para expor a sua rotina, os lugares a que vai e os serviços que contrata.

Figura 2: Merchandising no perfil de Fernanda Souza

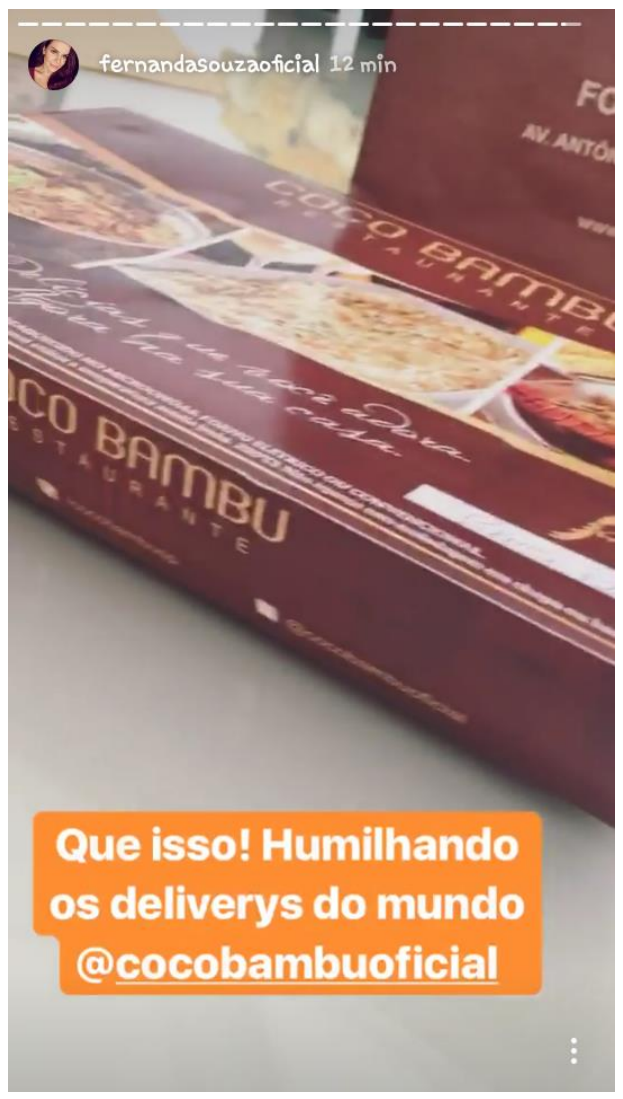

Fonte: Instagram

Página 135 Caderno de Ciências Sociais Aplicadas, Vitória da Conquista/BA, vol. 15, n 25, ano 15, p. 122-141, jan/jun 2018. 
A figura acima é retirada de um vídeo que a atriz postou em sua história, mostrando a embalagem de um delivery de comida. Em seu discurso, Fernanda enfatiza que a embalagem é muito bem-feita e que, embora se assemelhe à de alimento congelado, se trata de alimento preparado na hora.

No vídeo, a atriz mostra a embalagem com a marca, faz um elogio, escreve que o delivery em questão humilhou os demais e exibe o link da empresa, mostrando que com apenas um clique os seguidores poderiam conhecer aquele serviço. Entre outras plataformas do Instagram, essa é, portanto, uma forte ação de merchandising e de persuasão. A publicação assume um caráter propagandístico, classificado de merchandising direto e proposital (DIAS, 2016).

Solange Almeida, ex-vocalista da banda "Aviões do Forró", é outra cantora com muitos seguidores (3,7 milhões) que utiliza o Insta Stories para promover marcas e produtos. À sua rotina de shows, a artista costuma incorporar ações de merchandising, com publicações de Stories. Com isso, ela divulga produtos tanto para o público presente em suas apresentações quanto para os seus seguidores no Instagram, o que amplia o alcance das marcas para as quais ela realiza ações de marketing.

Esse foi o caso do Storie publicado no dia 3 de junho, em que Solange divulga uma marca de lingerie. A cantora mostra o produto aos fãs, incentiva-os a adquirir aquela marca e indica de que forma é possível conseguir um produto igual ao supostamente utilizado por ela (FIGURA 3).

Página 136 Caderno de Ciências Sociais Aplicadas, Vitória da Conquista/BA, vol. 15, n 25, ano 15, p. 122-141, jan/jun 2018. 


\section{- Cadernos de Ciénclas SOCIAIS APLICADAS}

Figura 3: Ação de merchandising no Insta Stories de Solange Almeida

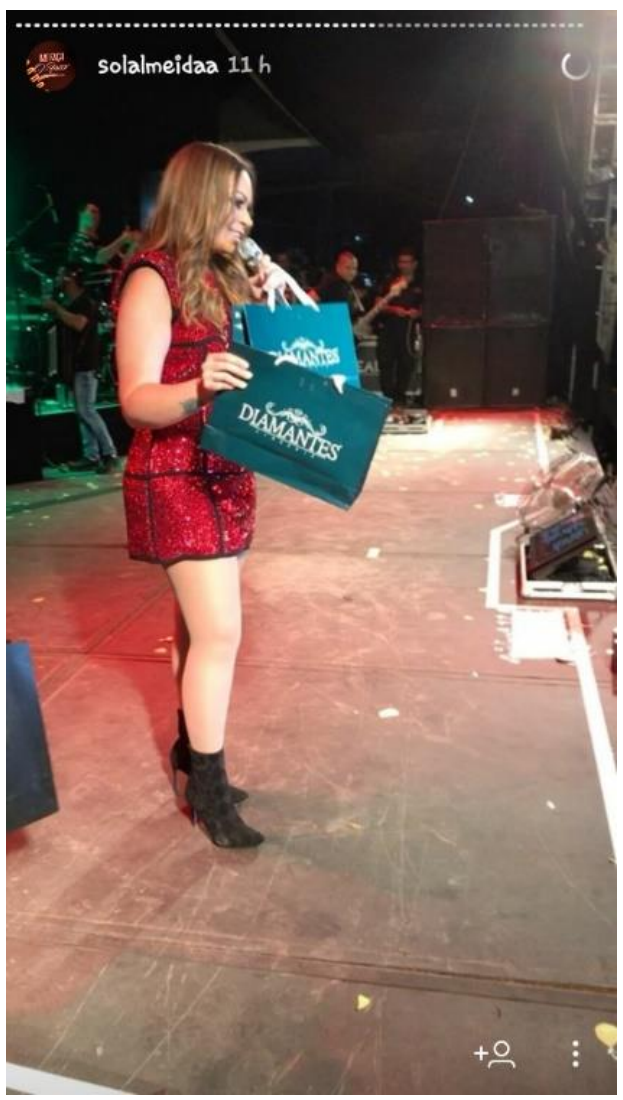

Fonte: Instagram

Em um vídeo curto, a cantora assim se refere à empresa: "a minha marca de lingerie". Movida certamente por um cachê, tal ação gera uma associação direta entre o produto e a artista. Classifica-se, portanto, como um merchandising direto e proposital, (DIAS, 2016). Para aqueles seguidores que se adéquam ao perfil do público-alvo do produto, essa ação de marketing configura uma forte influência para o consumo da marca pelo sentimento de satisfação em usar um bem material igual ao do artista do qual é fã. Em outro Storie, Solange Almeida distribui algumas sacolas para as pessoas presentes no show, uma atitude de carisma e de simpatia que referencia os gostos pessoais da cantora. Nesse mesmo Storie, aciona-se o link da marca e aparecem dois emojis que representam o coração, simbolizando o que seria o amor da artista pela marca, estratégia subliminar que também revela uma ação de merchandising.

Diferentemente de Solange Almeida, Bruna Marquezine costuma explorar em seus Insta Stories o merchandising puro, aquele em que se promove uma marca ou um produto por meio de uma publicização direta, associada ao seu cotidiano e à sua vida pessoal. O Insta Stories da atriz compõe se de situações em que o merchandising é, quase sempre, direto e proposital. Por ser a segunda brasileira com mais Página 137 Caderno de Ciências Sociais Aplicadas, Vitória da Conquista/BA, vol. 15, n 25, ano 15, p. 122-141, jan/jun 2018. 


\section{Cadernos de Ciências SOCIAIS APLICADAS}

seguidores no Instagram, Bruna Marquezine tem um enorme potencial para estimular o consumo das marcas que promove.

Figura 4: Merchandising no perfil da atriz Bruna Marquezine

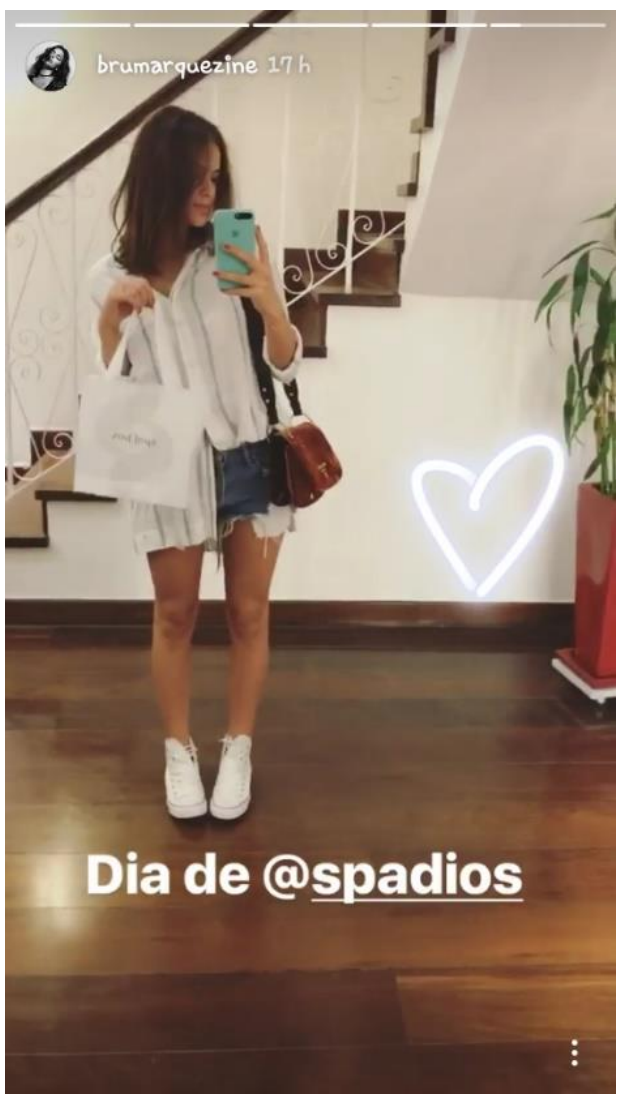

Fonte: Instagram

$\mathrm{Na}$ imagem acima, a atriz divulga uma empresa que presta serviços de $S P A$, dos quais, em tese, ela usufrui. Esse simples fato reforça a sua grande influência para convencer os fãs que a seguem no Instagram a consumir os serviços da empresa.

"Muito mais do que simplesmente exibir detalhes favoráveis de suas vidas, os digital influencers combinam isso à oportunidade de capitalizar seus perfis com marcas e serviços que refletem e complementam seus gostos pessoais, e assim alcançam seus seguidores, que tomam sua opinião como referência" (DIAS, 2016, p. 10).

A ação principal de merchandising no destaque acima está em promover o visual da empresa (tal qual seu perfil no Instagram, conforme link no Storie) e a imagem da artista. O fato de ela usufruir dos

Página 138 Caderno de Ciências Sociais Aplicadas, Vitória da Conquista/BA, vol. 15, n 25, ano 15, p. 122-141, jan/jun 2018. 
serviços em questão e incorporar a referida marca ao seu dia a dia funciona tal qual um elemento catalisador para os seus seguidores.

\section{Considerações finais}

As ações de merchandising nas redes sociais estão cada vez mais evidentes. As marcas valem-se da influência de pessoas com um grande número de seguidores para, mediante publicações, vídeos, fotos, hiperlinks (direcionamento ao perfil da marca), divulgar produtos.

Dessa forma, cada vez mais, surgem indivíduos interessados em utilizar o prestígio que adquiriram ao longo de sua história a favor de empresas para obter benefícios. Desse processo emergem os digital influencers, pessoas que atuam em um mercado voltado para o marketing nas mídias sociais e na internet.

O Instagram, uma rede social mais rápida, efetiva e essencialmente visual, é a plataforma que atrai grandes investimentos para divulgação de marcas, o principal nicho de atuação desses influencers.

A análise mostrou que, sutilmente ou mesmo de forma mais clara, pessoas famosas, principalmente as do meio artístico, se autopromovem na condição de digital influencers e divulgadores de marcas. Viabilizadas por meio de ferramentas da rede social, as estratégias de marketing baseiam-se no carisma e na imagem do influenciador e na interação deste com o público. Desse modo, a ação de merchandising consegue ser mais visual e imediata e obter o retorno do consumidor mais rapidamente que as demais técnicas mercadológicas.

\section{Referências}

BALDANZA, Renata Francisco; ABREU, Nelsio Rodrigues. Comunidades virtuais: reflexões sobre multiculturalismo e cosmopolitismo na rede. In: ENCONTRO DE ESTUDOS MULTIDISCIPLINARES EM CULTURA, 2., 2006, Salvador. Anais... Salvador: UFBA, 2006. Disponível em: <http://www.cult.ufba.br/enecul2006/renata_francisco_baldanza.pdf>. Acesso: 13 maio 2017.

BOURDIEU, Pierre. In: THIOLLENT, Michel. Crítica metodológica, investigação social e enquete operária. São Paulo: Polis, 1981. p. 137-151.

CASTRO, Gisela GS. Entretenimento, sociabilidade e consumo nas redes sociais: cativando o consumidor-fã. Fronteiras-estudos midiáticos, São Leopoldo, v. 14, n. 2, p. 133-140, maio/ago. 2012.

Disponível em:

Página 139 Caderno de Ciências Sociais Aplicadas, Vitória da Conquista/BA, vol. 15, n 25, ano 15, p. 122-141, jan/jun 2018. 
<http://www.revistas.unisinos.br/index.php/fronteiras/article/view/fem.2012.142.07>. Acesso: 14 maio 2017.

DIAS, Vitor Nogueira. Consumo turístico e os digital influencers: uma análise exploratória de perfis no Instagram. 2016. 16 p. Artigo (Bacharelado Interdisciplinar em Ciências Humanas) Universidade Federal de Juiz de Fora, Juiz de Fora, 2016. Disponível em: <http://www.ufff.br/bach/files/2016/10/VITOR-NOGUEIRA-DIAS.pdf>. Acesso: 14 mai. 2017.

FREITAS, Gabrielle Alves Rosendo; MAIA, Aline. Interatividade nas redes sociais: os memes como o novo intertexto. In: CONGRESSO BRASILEIRO DE CIÊNCIAS DA COMUNICAÇÃO, 37., 2014, Foz do Iguaçu. Anais... Foz do Iguaçu: INTERCOM, 2014. Disponível em: <http://www.intercom.org.br/sis/2014/resumos/R9-2422-1.pdf>. Acesso:13 maio 2017.

GIL, Antônio Carlos. Métodos e técnicas de pesquisa social. 6. ed. São Paulo: Atlas, 2008.

GUEDES, Éllida Neiva. Espaço público contemporâneo: pluralidade de vozes e interesses. Biblioteca

Online de Ciências da Comunicação, p. 1-16, 2010. Disponível em: <http://bocc.ubi.pt/pag/guedes-ellida-espaco-publico-contemporaneo.pdf>. Acesso: 13 maio 2017.

HABERMAS, Jürgen. Mudança estrutural da esfera pública: investigações quanto a uma categoria da sociedade burguesa. Tradução: Flávio R. Kothe. Rio de Janeiro: Tempo Brasileiro, 2003.

ISIDORO, Carolina Zafino; SILVA, Magno Luiz Medeiros da. Internet e comunicação pública: o uso das redes sociais. In: CONGRESSO BRASILEIRO DE CIÊNCIAS DA COMUNICAÇÃO, 38. 2015, Rio de Janeiro. Anais... Rio de Janeiro: INTERCOM, 2015. Disponível em: <http://portalintercom.org.br/anais/nacional2015/resumos/R10-3082-1.pdf>. Acesso: 13 maio 2017.

LEMOS, André. Nova esfera conversacional. In: KUNSCH, Dimas et al. Esfera pública, redes e jornalismo. Rio de Janeiro: E-Papers, 2009, p. 9-30. Disponível em: <http://www.academia.edu/download/23096439/novaesferaconversacional.pdf>. Acesso: 13 maio 2017.

LEMOS, André; LÉVY, Pierre. O futuro da internet: em direção a uma ciberdemocracia planetária. São Paulo: Paulos, 2010.

LÉVY, Pierre. Cibercultura. 3. ed. São Paulo: Editora 34, 1999.

MARINHO, Nathilucy do Nascimento. O visual merchandising e a comercialização de moda-vestuário nas plataformas digitais. In: ENCONTRO DE ENSINO, PESQUISA E EXTENSÃO DA FACULDADE SENAC, 10., 2016, Recife. Anais...Recife: Faculdade Senac Pernambuco, 2016. p. 61$71 . \quad$ Disponível em: $<$ http://encontro.faculdadesenacpe.edu.br/doc/anais/ANAIS $\% 20 \mathrm{X} \% 20$ encontro $\% 20 \% 202016$. pdf>. Acesso: 13 maio 2017.

Página 140 Caderno de Ciências Sociais Aplicadas, Vitória da Conquista/BA, vol. 15, n 25, ano 15, p. 122-141, jan/jun 2018. 
OLIVEIRA, Maxwell Ferreira de. Metodologia Científica: um manual para realização de pesquisas em Administração. Catalão: Universidade Federal de Goiás, 2011. Disponível em: <https://adm.catalao.ufg.br/up/567/o/Manual_de_metodologia_cientifica_Prof_Maxwell.pdf>. Acesso: 24 nov. 2017.

PIZA, Mariana Vassallo. O fenômeno Instagram: considerações sob a perspectiva tecnológica. 2012. 48 p. Monografia (Bacharelado em Ciências Sociais) - Universidade de Brasília, Brasília, 2012. Disponível em: <http://bdm.unb.br/handle/10483/3243>. Acesso: 14 maio 2017.

RAMPAZZO, Lino. Metodologia científica para alunos dos cursos de graduação e pósgraduação. 3. ed. São Paulo: Loyola, 2005.

RECUERO, Raquel da Cunha. Redes sociais na internet. Porto Alegre: Sulina, 2009. (Coleção Cibercultura) 191 p. E-book disponível em: <http://www.ichca.ufal.br/graduacao/biblioteconomia/v1/wpcontent/uploads/redessociaisnainternet recuero.pdf>. Acesso em: 24 abr. 2017.

SAMPAIO, Juliana Paradinha; BARUQUE-RAMOS, Julia. A tecnologia aplicada às ações de Visual Merchandising de moda. CONTEXMOD, v. 1, n. 2, p. 1-16, maio 2014. Disponível em: <http://www.contexmod.net.br/index.php/segundo/article/view/80>. Acesso: 13 maio 2017.

SILVA, Carlos Alberto F. da; TANCMAN, Michéle. A dimensão sociespacial do Ciberespaço: uma nota. GEOgraphia, v. 1, n. 2, p. 55-66, 1999. Disponível em: <http://www.geographia.uff.br/index.php/geographia/article/view/18>. Acesso: 22 nov. 2017.

SOARES, Afra de Medeiros. O riso na cibercultura: processos de construção do humor brasileiro na internet. Revista Eletrônica Inter-Legere, v. 1, n. 14, p. 1-21, jan-jun 2014. Disponível em: <www.periodicos.ufrn.br/interlegere/article/download/5316/4295>. Acesso em: 13 maio 2017.

DOI: https://doi.org/10.22481/ccsa.v15i25.3982

TOLEDO, Geraldo Luciano; NAKAGAWA, Marcelo Hiroshi; YAMASHITA, Sandra Sayuri. O composto de marketing no contexto estratégico da internet. Revista de Administração Mackenzie, v. 3, n. $1, \quad$ p. 33-78, 2002. Disponível em: <http://editorarevistas.mackenzie.br/index.php/RAM/article/view/18>. Acesso em: 14 maio 2017. 